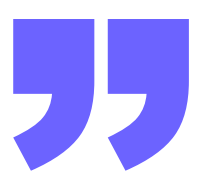

\title{
AN ANALYSIS OF SLANG WORDS FOUND IN THE MOVIE SCRIPT OF “THE FAST AND THE FURIOUS" BY ROB COHEN
}

\author{
Denny Syahputra ${ }^{1}$, Ni Wayan Suastini ${ }^{2}$, I Komang Sulatra ${ }^{3}$ \\ Mahasaraswati Denpasar University, Indonesia123 \\ saputradeny802@gmail.com
}

\begin{abstract}
This study aimed at identifying the types of slang and the process of creating slang word found in a movie script entitled The Fast and The Furious by Rob Cohen. This study employed descriptive and qualitative method. The data of this study were obtained by watching and taking notes of slang word spoken by the characters in the movie "The Fast and The Furious". There are two types of slang word, namely primary and secondary, using the theory by Chapman (2007), and in a matter of process of creating slang, the theory by Yule was adopted (1985). The data of this study were obtained by observation method through four steps, namely watching The Fast and The Furious. Next, finding and taking notes of slang words spoken by the characters in the movie The Fast and The Furious. Reading the online movie script and finally, the writer categorized the types of data. There were two types of slang words encountered, namely primary and secondary slang. The result of the study demonstrated that there are 5 slang words found in the movie The Fast and The Furious with 3 primary slang and 2 secondary slang.
\end{abstract}

\section{INTRODUCTION}

People have diverse ways on expressing their thoughts among fellow both in formal and informal context. As an optional medium to conversate, people tend to perform slang to express colloquialism which is mostly occurred in English speaking country (Liz, 2018:1). Slang belongs to 
language varieties that is generally used by teenagers or specific group of people who take delight to play with words or combine it with phrases. Slang additionally functions to reveal someone's background and social gap. It is due to a specific types of slang are formed by the speakers to express something without being comprehended by unintended people.

In every part of the world, every culture, every era and even every region has their own slang. Since it belongs to far beyond English formal, hence slang frequently appears in movie scripts, song lyrics, novels, etc. The use of slang words in this modern era can be found in many literary works, such as novels, song lyrics, articles, magazines, newspapers and movies. From those many literary works, the writer selected the movie to analyze the use of slang words in the form of an utterance spoken by the characters throughout the movie selected. In this research, the writer analyzed English slang words found in a movie entitled The Fast and The Furious. There is one problem in this research to reveal, namely (1) What types of slang language found in the movie script of The Fast and The Furious by Rob Cohen? (2) What are the meanings of the slang found in The Fast and The Furious? This research was conducted to reveal the types of slang words found in a movie entitled The Fast and The Furious. This movie is spoken in English and the subtitle was written by Scripts.com in 2018.

This research has a thing in common with another research conducted by Trimastuti (2017) entitled An Analysis of Slang Words Used In Social Media. In his journal, he has two research objectives. There is a meaning of the slang used in social media and the types of slang. He uses descriptive qualitative method to analyze slang. In his article, he found the meaning of each slang in the social media. He also found three forms of slang, namely: abbreviation, alphabet changing and irregular capital letter usage. The essence of communication is transmission of meaning from one individual to another. Talk is the primary means by which people interact and satisfy personal and social goals. People interact primarily through talk, most often in informal conversation. Trimastuti journal chose social as its data source to analyze slang, in contrast to this study, it will analyze the slang used in the film script.

Another research conducted by Lestari (2016) entitled A Study of Slang Words in Song Lyrics Used by Bruno Mars. The study discussed the types of slang words and dominant slang words found in Bruno Mars song lyric using the descriptive qualitative method. The theory used in Aprilia's study showed that 58 data was taken, but not all slang word-formation process appeared in lyrics. The processes of slang word formation used in the lyrics were clipping, blending, coinage, borrowing, and acronyms. The most dominant slang word found in Bruno Mars's lyrics song was clipping. 
Another research conducted by Krisdianka (2019) is entitled An Analysis Of Slang Words Used In Black Panther Movie. This study discusses the meaning of slang words and the context of the situation found in the Black Panther movie. The writer used descriptive qualitative method to analyze the data. In this study, Krisdianka found 15 data. The writer used "Oxford Slang Dictionary" (1998) to reference the article.

\section{METHODS}

The data of this study was retrieved entirely from The Fast and The Furious directed by Rob Cohen released in 2019. The length of this movie is one hour and forty six minutes. This movie is spoken in English, and it tells a story about a high-speed truck robbery performed by Dominic Toretto. Meanwhile another character named Brian $\mathrm{O}^{\prime}$ Conner as an undercover police officer of LAPD is in attempt to gain closer to Toretto to get apprehended.

This research employed observation method, which is by conducting direct research, as for the steps of collecting the data are as follow (1) Watch The Fast and The Furious, the first step in collecting the data is the writer watched the movie entitled The Fast and The Furious. (2) Find and take note the data of slang words in The Fast and The Furious, the next step is the writer seeked the data of phrasal verb spoken by the characters in The Fast and The Furious. After finding the data, the writer took note of each data found. (3) Read the movie script, the third step is the writer read the online movie script to ensure the data are valid. (4) Categorize the types of data, and finally, the writer categorized the types of each data found based on their constituent elements.

After the data have been thoroughly collected, the next step is to analyze the data. The analysis is conducted using descriptive qualitative method to systematically create description and the relationship with the object being investigated. The findings are discussed by identifying and categorizing the types of slang words based on the theory by Kipfer and Chapman (2007), who classifies the slang into primary and secondary.

Furthermore, the data found are presented in both formal and informal method. For formal method is a method in analyzing the findings by using a table, however formal method is most likely to require assistance from informal method using a descriptive sentence to discuss each data. 


\section{RESULTS AND DISCUSSION}

\section{RESULT}

The result of the research is to answer the problem of the study formulated in advance. In conducting the research, the writer found a number of slang words whose type belongs to primary and secondary slangs.

\begin{tabular}{c|c|cc}
\multicolumn{1}{c}{ No. } & Types of Slang Word & Frequency & Percentage \\
\hline 1. & Primary Slang & 3 & $60 \%$ \\
\hline 2. & Secondary Slang & 2 & $40 \%$ \\
\hline & Total & 5 & $100 \%$
\end{tabular}

The table above denotes the types, frequency, and percentage of slang words in the movie entitled The Fast and The Furious. It is found as many as 5 data of phrasal verbs that can be distinguished into two types namely Primary Slang and Secondary Slang. The most frequently occurred from both types of slang word is primary slang, which appeared by 3 times throughout the movie. Meanwhile, the secondary only appeared by 2 times throughout the movie.

\section{a. Discussion}

The writer presented the slang word in a form of sentence as uttered by the movie's character. The writer depended on the theory by Kipfer and Chapman (2007) to be able to distinguish primary slang and secondary slang.

\begin{tabular}{|c|c|c|c|}
\hline No. & Slang word found in the movie & Type of Slang & Meaning \\
\hline 1. & Gotta & Primary & Got + to \\
\hline 2. & Cop & Primary & Police \\
\hline 3. & Buster & Secondary & $\begin{array}{c}\text { An unpleasant } \\
\text { person }\end{array}$ \\
\hline 4. & Pumpkin & Secondary & Dear \\
\hline 5. & Yo & Primary & Greeting \\
\hline
\end{tabular}

The table above features the slang words discovered in a movie entitled The Fast and The Furious as well as their type.

Data 1

Dom

Jesse

: We'll put it on my tab at Harry,s

Dom

:Yes!

: I gotta get you racing again.

The utterance spoken by the Toretto above comprises a slang word namely gotta. The utterance performed by one of the characters above 
occurred when Toretto promises another character that he will be able to race again and come out with his new engine.

Kipfer \& Chapman (2007) states that gotta is slang since gotta is a contraction between got and to and is not used in a formal context. They additionally state that this type of slang is grouped into primary slang since both native and non-native English speakers are familiar with this term.

The term gotta is originated from got and to that means must. The transformation of this word does not change the meaning between informal and formal word. In addition, as states by Yule (1985) gotta is formed through a process namely blending in which combining two different words to produce a single new word. Blending is typically performed by saying only the beginning of one new word and it joins the end of the following words.

Data 2

Police

: We had a reported homicide.187, at barabian Liqours. (Radio police)

Another Character : Cops are all over it. We're good to roll.

The utterance spoken by one of the characters above contains a slang word namely cop. In the fragment of the movie above, one of the characters received information over the radio that there was a murder in the Barabian Liqours area. And the police force is heading there. The actor informed that the illegal racing area was safe and ordered to start the race.

According to Your Dictionary, the word cop actually means to seize or take, and evolved into being used as slang for police due to the fact that their job involves arresting people. The slang word is performed by another character in the movie informing that the police have surrounded the Barbarian Liquors venue.

Kipfer \& Chapman (2007) affirms that this type of slang is included into primary slang since the slang word cop belongs to original slang due to it is not formed through any of process of creating slang word that have been previously explained.

Data 3

Vince : Why did you bring the buster here?

Dom : :Cause he kept me out of handcuffs!

In this scene of the movie, there is one character saying why did you bring the buster here? covers a slang word namely buster. Vince performs the utterance to his companion named Dominic who brings unpleasant person named Brian to a party and Vince appears to be unhappy and uttering him Buster. 
According to Cambridge Dictionary (2021) the word buster actually means a person or thing intended to destroy the stated thing on the scene Vince called Brian with buster to insult him among people. And as stated by Kipfer \& Chapman (2007)-this type of slang grouped into secondary slang since this word is not widely known by the people and rarely used by native and non-native English speakers, only used by a few groups of people. This word is often used in an informal situation.

The slang word buster belongs to original slang because it is not formed through any process of creating slang words previously explained.

Data 4

Leon :I thought you weren't hungry, Pumpkin.

Vince :You know. I gotta eat.

In the statement shown above, there can be found a slang word namely pumpkin. It is intended to a character named Vince whom previously had said that he was not hungry and do not want to eat together at the same 8table with Brian. A few minutes later Vince changed his mind and came to the table to join in the table.

According to EnglishClub.com the word pumpkin is a Term of Endearment. In English, the word pumpkin is often used as a term of endearment. Other English words that people use to express their adoration for someone include babe, baby, beautiful, buddy, cupcake, cutie-pie, dear, honey, pet, princess, sugar, sweet pea, sweetie, or sweetie-pie.

On that scene, Leon called Vince as pumpkin since they are best friend and to make some jokes. And as stated by Kipfer \& Chapman (2007) this type of slang is grouped into secondary slang since this word is not widely known by the people and also rarely used by both native and nonnative English speakers, only used by a few groups of people. This word is often used in informal situation.

Data 5

Leon

Dom

: Yo Dom. We were just about to go looking for you, brother. : We were you?

The utterance spoken by the one of characters above contains a slang word namely yo. The sentence above is spoken by a character greeting another character named Dominic who just arrived and saying that his fellows has gone looking for him. In fact, Dominic was on the escape from being chased by the authorities and had been saved by Brian at that time.

According to Your Dictionary the word yo used variously to attract attention, greet someone, introduce or emphasize a remark, etc. Meanwhile, Kipfer and Chapman (2007:8) examine this type of slang as a primary slang 
since both native and non-native English speakers are familiar with this term.

\section{CONCLUSION}

In accordance to the results of the data analysis of the slang words used in the movie entitled The Fast and The Furious, there are multiple types of slang whose type primary and secondary slang. The total amount of slang words found in The Fast and The Furious movie is 5 consisting of 3 primary slang and the other three are secondary. The primary slang occurred dominantly because this type of slang is often used by people to simplify their conversation in everyday life.

\section{REFERENCES}

Club, E. (2021). Retrieved from English Club: https://www.englishclub.com/about/faq.php

Dictionary, C. (2021). Retrieved from Online Dictionary: https:// dictionary.cambridge.org/

Dictionary, Y. (2020). Retrieved from Online Dictionary: https://www.yourdictionary.com/

Fromkin, V., \& R. Rodman. 2003. An Introduction to Language: Cengage Learning.

Halliday. M. A. 1989. Language, Context, and Text. Aspects of Language in a Social Semiotic Perspective: Oxford University Press.Hornby, (2000) Oxford Advanced Learner's Dictionary

Kipfer, B. A., \& R. L. Chapman. 2007. Dictionary of American Slang. London: Pan Macmillan.

Krisdianka, Bob. 2016. “An Analysis Of Slang Words Used In Black Panther

Movie". Riau: Student of English Language Education Department Faculty of Teachers Training and Education Universitas Riau.

Lestari, Aprilia. 2016. “A Study of Slang Words In Song Lyrics Used by BrunoMars". (Thesis) Surabaya: English Department Faculty of Letters And Humanities State Islamic University SunanAmpel Surabaya.

Liz. M. 2018. Expressing your Point of View in an English Conversation. Retrieved

from: $\quad$ https://live-english.net/expressing-point-view-englishconversation/ 
Trimastuti, Wahyu. 2017. “An Analysis of Slang Words Used In Social Media.

Bandung: Piloteknik Piksi Ganesha Bandung.

Yule, George (1986). The Study of Language. Cambridge: Cambridge University Press.

"The Fast and the Furious" Scripts.com. August 05, 2018 STANDS4 LLC, 2021. Web. Retrieved on 16 Jun 2021. From <https://www.scripts.com/script/the_fast_and_the_furious_8034 $>$. 